\title{
How do green roofs mitigate urban thermal stress under heat waves?
}

\author{
Article \\ Published Version
}

Sun, T., Grimmond, C. S. E. and Ni, G.-H. (2016) How do green roofs mitigate urban thermal stress under heat waves? Journal of Geophysical Research: Atmospheres, 121 (10). pp. 5320-5335. ISSN 2169-8996 doi: https://doi.org/10.1002/2016JD024873 Available at https://centaur.reading.ac.uk/65530/

It is advisable to refer to the publisher's version if you intend to cite from the work. See Guidance on citing.

Published version at: http://dx.doi.org/10.1002/2016JD024873

To link to this article DOI: http://dx.doi.org/10.1002/2016JD024873

Publisher: American Geophysical Union

All outputs in CentAUR are protected by Intellectual Property Rights law, including copyright law. Copyright and IPR is retained by the creators or other copyright holders. Terms and conditions for use of this material are defined in the End User Agreement.

\section{www.reading.ac.uk/centaur}

\section{CentAUR}

Central Archive at the University of Reading 
Reading's research outputs online 


\section{Journal of Geophysical Research: Atmospheres}

\section{RESEARCH ARTICLE \\ 10.1002/2016JD024873 \\ How do green roofs mitigate urban thermal stress under heat waves?}

Key Points:

- GRs decrease near-surface air temperature, wind speed, and apparent temperature but increase atmospheric humidity

- Modifications by GRs scale almost linearly with the their surface cover fraction

- GRs reduce both the surface and atmospheric heating under HWs

Correspondence to:

T. Sun,

sunting@tsinghua.edu.cn

Citation:

Sun, T., C. S. B. Grimmond, and G.-H. Ni (2016), How do green roofs mitigate urban thermal stress under heat waves? J. Geophys. Res. Atmos., 121, 5320-5335, doi:10.1002/2016JD024873.

Received 28 JAN 2016 Accepted 27 APR 2016 Accepted article online 3 MAY 2016 Published online 19 MAY 2016

\author{
Ting Sun ${ }^{1,2}$, C. S. B. Grimmond ${ }^{2}$, and Guang-Heng $\mathrm{Ni}^{1}$ \\ ${ }^{1}$ State Key Laboratory of Hydro-Science and Engineering, Department of Hydraulic Engineering, Tsinghua University, \\ Beijing, China, ${ }^{2}$ Department of Meteorology, University of Reading, Reading, UK
}

\begin{abstract}
As the climate warms, heat waves (HWs) are projected to be more intense and to last longer, with serious implications for public health. Urban residents face higher health risks because urban heat islands exacerbate HW conditions. One strategy to mitigate negative impacts of urban thermal stress is the installation of green roofs (GRs) given their evaporative cooling effect. However, the effectiveness of GRs and the mechanisms by which they have an effect at the scale of entire cities are still largely unknown. The Greater Beijing Region is modeled for a HW scenario with the Weather Research and Forecasting model coupled with a state-of-the-art urban canopy model (Princeton Urban Canopy Model) to examine the effectiveness of GRs. The results suggest that GR would decrease near-surface air temperature $\left(\Delta \mathrm{T} 2_{\max }=2.5 \mathrm{~K}\right)$ and wind speed $\left(\Delta \mathrm{UV} 10_{\max }=1.0 \mathrm{~m} \mathrm{~s}^{-1}\right)$ but increase atmospheric humidity $\left(\Delta \mathrm{Q} 2_{\max }=1.3 \mathrm{~g} \mathrm{~kg}^{-1}\right)$. GRs are simulated to lessen the overall thermal stress as indicated by apparent temperature $\left(\triangle \mathrm{AT} 2_{\max }=1.7^{\circ} \mathrm{C}\right)$. The modifications by GRs scale almost linearly with the fraction of the surface they cover. Investigation of the surface-atmosphere interactions indicates that GRs with plentiful soil moisture dissipate more of the surface energy as latent heat flux and subsequently inhibit the development of the daytime planetary boundary layer (PBL). This causes the atmospheric heating through entrainment at the PBL top to be decreased. Additionally, urban GRs modify regional circulation regimes leading to decreased advective heating under HW.
\end{abstract}

\section{Introduction}

Cities differ from their surroundings in terms of built forms, materials, and intensive anthropogenic activities. These differences result in the well-known urban heat island (UHI) effect, whereby cities are often warmer than their surroundings [Oke, 1982]. Heat waves (HWs), excessively hot periods, are exacerbated by the $\mathrm{UHI}$ effect and cause cities to be more vulnerable to HWs resulting in greater thermal stresses for urban residents [Li and Bou-Zeid, 2013]. This is of particular concern for those residents susceptible to heat-related illness, given that heat waves are more likely to occur with higher intensities in the coming decades [Meehl and Tebaldi, 2004], and worldwide, more people are living in urban environments. Measures to mitigate HWs in cities warrant urgent attention.

Beijing, the capital of China, has been rapidly growing since the 1970s, with a population of 20 million in 2012 [Dou et al., 2015]. Accompanying this have been modifications to the underlying surfaces [Tan et al., 2011], with well-documented impacts on the local climate (e.g., wind regime [Hou et al., 2013] and rainfall [L. Yang et al., 2014]). HWs in Beijing have increased in intensity, occurrence, and duration since the 1990s (Figure 1), evident from analysis of 60 years (1950-2010) of air temperature observations in Beijing (World Meteorological Organization index No. 54511, for a description refer to Wang and Gong [2010]). A range of strategies to mitigate the negative effects of UHI and HWs have been designed and implemented [Rizwan et al., 2008], including green roof (GR) systems (any type of roof with vegetation layers installed [Saadatian et al., 2013]). Implemented worldwide, GRs enhance evaporative cooling while not occupying ground level space often much in demand for other uses. GRs are categorized (commonly) by their construction complexity-intensive and extensive [Carson et al., 2013]. Extensive GRs, with thinner substrate layers $(\sim 0.15 \mathrm{~m})$ and short rooting vegetation, are easier to install and have lower cost; thus, they are more widespread. These are the focus in this study.

The effectiveness of GRs in mitigating thermal stress is well documented in a variety of cities under different climates (e.g., reviews of Qiu et al. [2013], Saadatian et al. [2013], and Berardi et al. [2014]). However, given most studies focus on the building-scale they lack consideration of the interactions between GRs, 

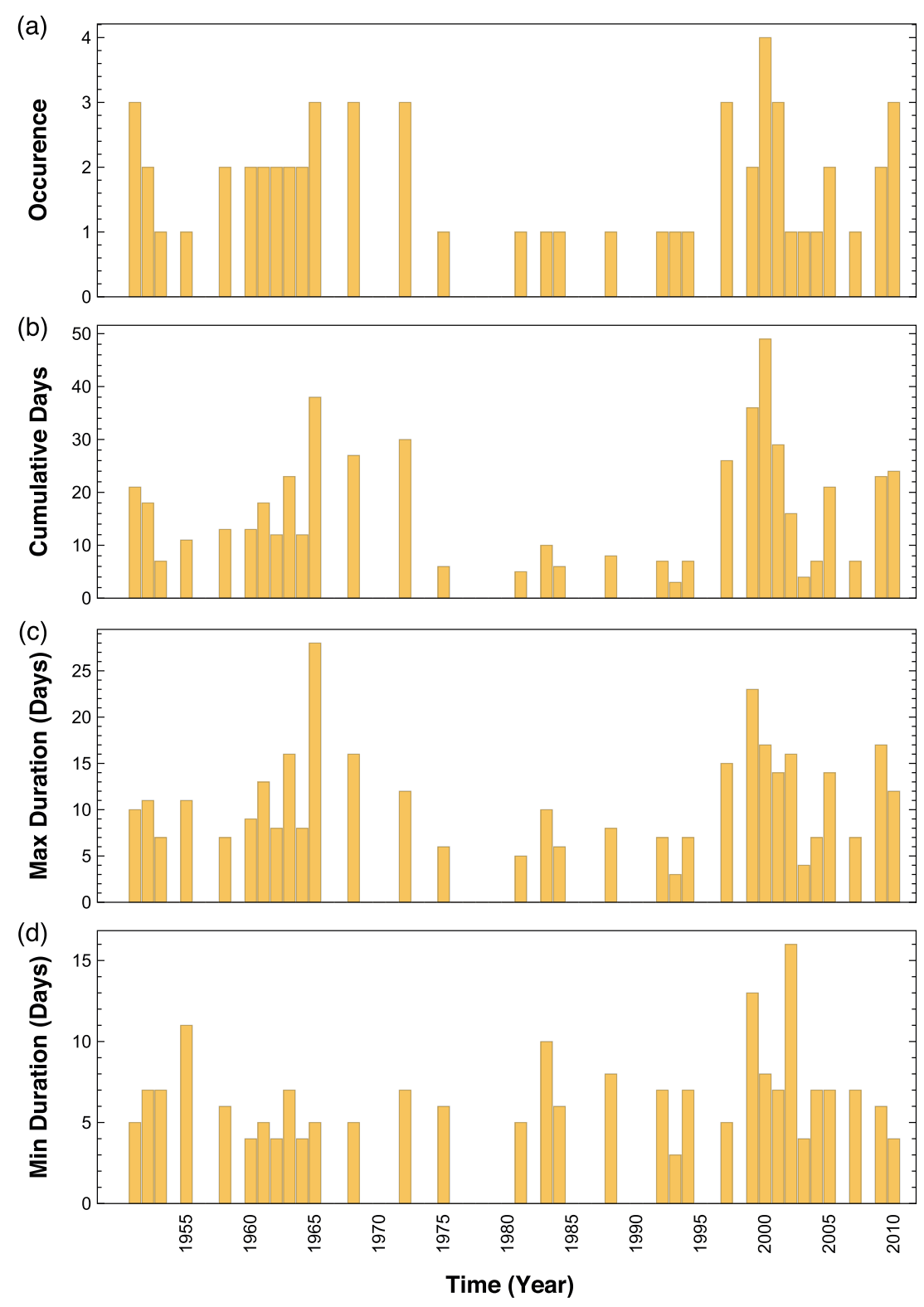

Figure 1. The annual statistics of heat waves in Beijing based on a 60 year air temperature data set from China Meteorological Administration: (a) occurrence, (b) cumulative days, (c) maximum, and (d) minimum duration in days. A location specific (Beijing) definition [Meehl and Tebaldi, 2004] is adopted to identify the HW periods. Two location specific thresholds of daily maximum air temperature $\left(T_{\max }\right)$ are introduced: $T_{1}$ the 97.5 th percentile of the observation series, and $T_{2}$ the 81st percentile. A HW is defined as the longest period satisfying the following three conditions: (1) $T_{\max }>T_{1}$ for at least 3 days, (2) $\bar{T}_{\max }>T_{1}$ for the entire period, and (3) $T_{\max }>T_{2}$ for the entire period, where $\bar{T}_{\max }$ denotes the average of $T_{\max }$ over the HW period. Note that this definition is also used in many other studies with minor alterations in the selection of $T_{1}$ and $T_{2}$ [Lau and Nath, 2012, 2014].

background climate, and the larger city scale. Although some larger-scale studies have considered GRs, treated either as high albedo surfaces [e.g., Smith and Roebber, 2011] or shallow water bodies [e.g., Georgescu et al., 2014], they have not included realistic biophysics of GRs as biomass-soil layers.

With climate and synoptic setting varying from city to city, the effectiveness of GRs needs to be investigated for a range of different scenarios in order to generalize findings about their impact at the city-scale. Through Weather Research and Forecasting-Princeton Urban Canopy Model (WRF-PUCM) simulations of the Greater Beijing Region (GBR), this paper considers whether, and how, GRs can mitigate the city-scale thermal stress 


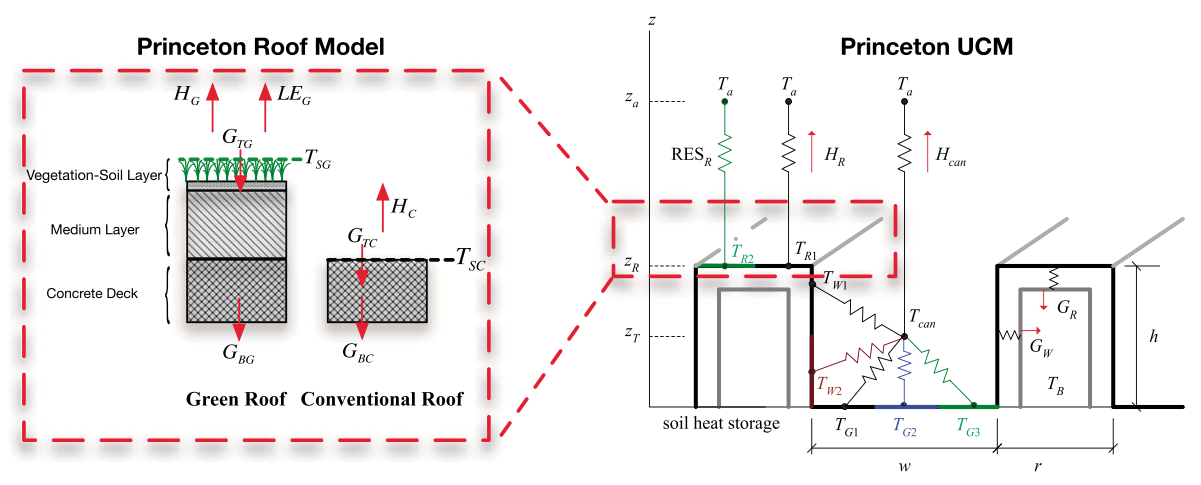

Figure 2. (left) Schematic of Princeton ROof Model (PROM) within the frame of (right) Princeton UCM (PUCM). In the schematic of PROM, heat fluxes are denoted with red arrows: $H$ for sensible heat flux, $L E$ for latent heat flux, and $G$ for heat flux through surface. The dashed line aligned with roof surface denotes surface temperature with notation $T_{s}$. The subscript $\mathrm{G}$ is for green roof, $\mathrm{C}$ for conventional roof, $\mathrm{T}$ for top surface, and B for bottom surface (for notations employed in PUCM schematic refer to Sun et al. [2013]). Reprinted from Sun et al. [2013], with permission from Elsevier.

under HWs. Thermal stress indicators are numerous [Buzan et al., 2015]. Here the apparent temperature (AT; details refer to Steadman [1984]) is selected for its applicability and feasibility. This is defined as

$$
\mathrm{AT}=T_{a}+\frac{3.3}{1000} e_{V}-0.7 \mathrm{U}-4
$$

where $T_{a}$ denotes the dry bulb air temperature in ${ }^{\circ} \mathrm{C}, e_{V}$ denotes the actual vapor pressure in $\mathrm{Pa}$, and $U$ denotes the wind speed in $\mathrm{m} \mathrm{s}^{-1}$.

The Princeton Urban Canopy Model (PUCM) accounts for the heterogeneity of urban surfaces while treating them in a single layer [Wang et al., 2011, 2012]. It allows GRs to be a roof facet alongside more conventional ones. PUCM when coupled with the mesoscale Weather Research and Forecasting model (WRF hereinafter, described in Skamarock and Klemp [2008]) can simulate the regional urban-atmosphere interactions, including GR-atmospheric interactions, at the city scale [Li et al., 2014; J. Yang et al., 2014]. Previously, Li and Bou-Zeid [2013] adopted this approach to simulate the Baltimore-Washington (USA) corridor during a HW to assess the effectiveness of GRs and high-reflective roofs in mitigating UHI effects at the city scale. They demonstrated the capability of the coupled WRF-PUCM in simulating regional urban-atmospheric dynamics. Extending beyond a single HW, Yang et al. [2016] use WRF-UCM (similar to PUCM) to simulate Phoenix and Houston (USA) for a year to examine the seasonality of the effects of GRs at regional scales.

In this paper, simulations for the Greater Beijing Region (GBR) are undertaken using WRF-PUCM (section 2) to allow the impact of GRs on the city-scale micrometeorology to be assessed and to gain insights into the mechanisms by which GRs have their effect (section 3).

\section{Methodology}

\subsection{Model Description}

The representation of urban areas in numerical weather prediction models is crucial in simulating urbanatmospheric interactions [Best and Grimmond, 2015]. Urban canyons with three types of homogeneous facets: roof, wall, and ground, have been widely used for urban land surface models. This approach, however, does not account for different materials in a single facet, common in urban areas (e.g., windows in a concrete wall), nor hydrological processes (e.g., evaporation after rainfall due to rainwater held by impervious surfaces), which have been shown to be crucial for the performance of urban models [Grimmond et al., 2011].

This study employs the WRF-PUCM system [Li and Bou-Zeid, 2013] as the simulation tool. Surface heterogeneity and urban hydrological processes are considered by PUCM [Wang et al., 2012]. PUCM includes the detailed Princeton Roof Model (PROM Figure 2a) for simulation of the hygrothermal dynamics over green and conventional roofs [Sun et al., 2013] to address the importance of roofs to urban surfaces [Porson et al., 

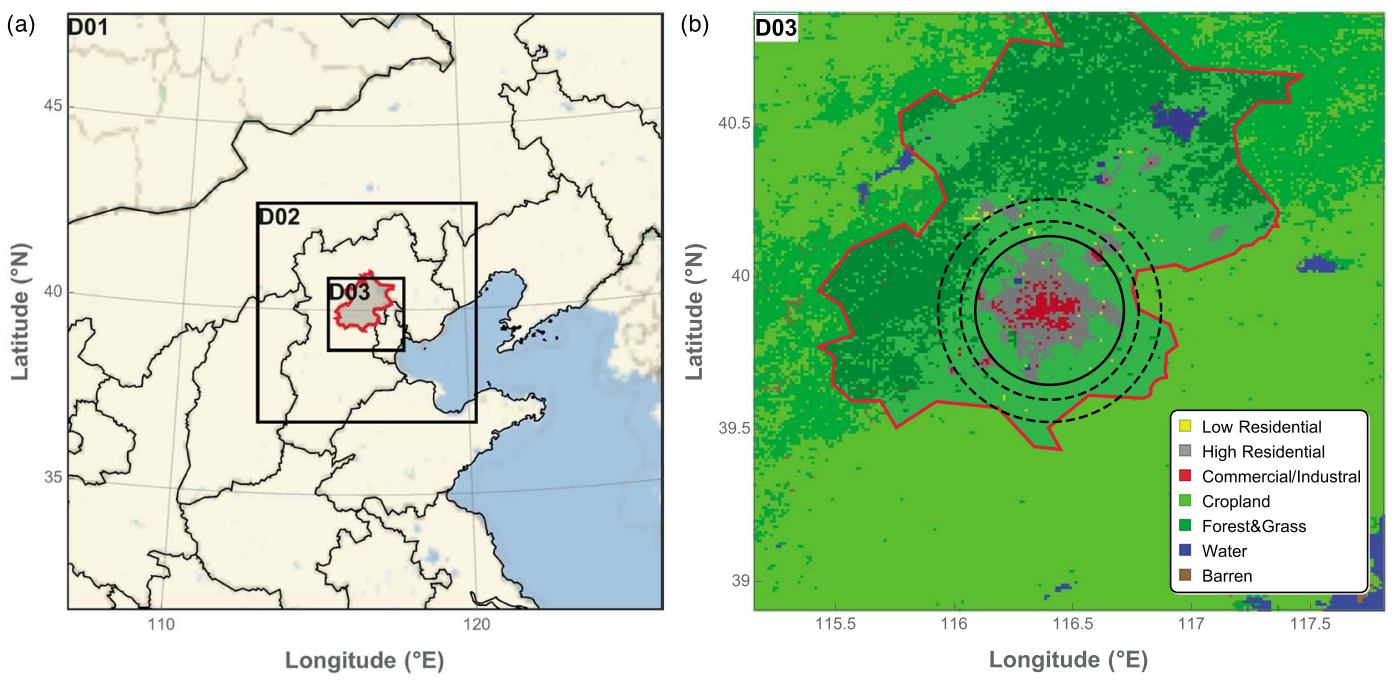

Figure 3. WRF-PUCM simulation configuration of (a) one-way nested domains delineated by black rectangles and (b) the land use map for domain D03. The red-edged polygon denotes the Greater Beijing Region. The black disk (radius: $27 \mathrm{~km}$ ) and dashed ring outline the urban and rural areas, respectively, for calculating UHI intensity.

2009; Loridan et al., 2010]. PUCM and PROM have both been evaluated off-line and found to provide reliable performance [Sun et al., 2013, 2014].

\subsection{WRF-PUCM Setup and Evaluation}

The study area, Greater Beijing Region (GBR) is represented in WRF-PUCM with three nested domains (horizontal grid resolutions of 9,3, and $1 \mathrm{~km}$; Figure 3a) for a period with no observed rainfall. Cumulus parameterization is not used for any domains as even the largest grid size is less than $10 \mathrm{~km}$ [Stensrud, 2007]. The largest domain (D01) covers most of central and northeastern China; D02 includes Hebei, most of Shandong and Shanxi, and parts of Henan, Inner Mongolia, and Liaoning provinces; D03 covers the GBR (Figure 3b). One-way nesting is used among the three domains. The grids contain 54 vertical levels with the upper boundary set as $100 \mathrm{hPa}$. The time steps for the three domains are 45,15 , and $5 \mathrm{~s}$, respectively. The initial and boundary conditions are from the Global Final Analysis (FNL) data [NCEP, 2000] at a spatial and temporal resolution of $1^{\circ} \times 1^{\circ}$ and $6 \mathrm{~h}$, respectively. The WRF version 3.4 physics parameterization schemes (Table 1) were used to simulate a HW in the hottest period of 2010 in Beijing (08:00 3 July to 00:00 7 July 2010 UTC; see Figure 1). During this period there was a persistent subtropical high over north China with southerly winds over GBR. The initial conditions, prescribed by FNL data, were used for a $16 \mathrm{~h}$ spin-up of WRF-PUCM prior to the 3 day $(72 \mathrm{~h}$ ) period analyzed. The GR soil moisture initial conditions were set to a relatively high value of $0.3 \mathrm{~m}^{3} \mathrm{~m}^{-3}$ ( $50 \%$ saturation) to ensure evaporation [Sun et al., 2013].

The PUCM implemented in WRF can use the default configuration convention of UCM [Chen et al., 2011] (e.g., low-density residential, high-density residential, and industrial and commercial) grids or alternatively use different settings for individual urban grids (UGs) to represent the city-scale heterogeneity. Hou [2012] determined the GBR (Figure $3 \mathrm{~b}$ ) fraction of impervious surfaces $\left(f_{\text {imp }}\right)$ for each $\left(1 \mathrm{~km}^{2}\right)$ grid, following Wu and Murray [2003] from a Landsat TM5 (28 May 2007, $30 \mathrm{~m}$ resolution) image. In this study, all parameters are assigned to the UGs based on $f_{\text {imp }}$ in three classes (Table 2 ): low-density residential $\left(f_{\mathrm{imp}} \leq 50 \%\right)$, high-density residential $\left(50 \%<f_{\mathrm{imp}}<80 \%\right)$, and industrial and commercial $\left(f_{\mathrm{imp}} \geq 80 \%\right)$. PUCM requires the vegetation within the "built" (in-canyon) area value to be specified. Based on a Beijing land cover survey, a value of $20 \%$ grassland prescribed for all UGs [Wang et al., 2014].

Previous evaluations of WRF-PUCM [Li and Bou-Zeid, 2014] indicated that the ground surface temperatures are sensitive to the planetary boundary layer $(\mathrm{PBL})$ scheme selected, implying that air temperature results can be improved with a PBL scheme. Thus, three PBL schemes (MYJ, YSU, and QNSE) were tested in the study region. MYJ simulates near surface meteorological conditions best (not shown here) and is used in the subsequent analyses. 
Table 1. Parameterization Schemes Used in This Study

\begin{tabular}{lc} 
Category & Scheme \\
\hline Longwave radiation & RRTM [Mlawer et al., 1997] \\
Shortwave radiation & Dudhia [Dudhia, 1989] \\
PBL & MYJ [Mellor and Yamada, 1982; Janjic, 1990] \\
Surface layer & Eta Similarity [Janjić, 1996, 2002] \\
Land surface & Noah [Chen and Dudhia, 2001; Ek et al., 2003] \\
$\begin{array}{l}\text { Urban module } \\
\text { Microphysics }\end{array}$ & PUCM [Wang et al., 2012] \\
Cumulus & WSM3 [Hong et al., 2004] \\
\hline
\end{tabular}

Air temperature (at $2 \mathrm{~m}$ above ground level (agl)), specific humidity (at $2 \mathrm{~m}$ agl), and wind speed (at $10 \mathrm{~m}$ agl) for 4 July 2010, observed at 34 standard meteorological stations across the GBR (Figure 4), were used to evaluate the current WRFPUCM setup. Simulated air temperatures have good agreement with the observations (Figure 4a), with correlation coefficients at most sites greater than 0.9 and normalized standard deviations (i.e., modeled standard deviation normalized by observed standard deviation) within a range between 0.8 and 1.2. Weaker agreement is evident in air specific humidity (Figure 4b) and wind speed (Figure 4c) (correlation coefficient $<0.7$ and normalized standard deviation 0.6-1.4 for specific humidity, and 0.6-1.0 for wind speed). The mean bias error indicates that temperature, specific humidity, and wind speed are all underestimated by WRF-PUCM. Using the hit rate (HR) metric allows wind direction to also be evaluated (details refer to Schlunzen and Katzfey [2003]). Using criteria of $2^{\circ} \mathrm{C}, 2 \mathrm{~g} \mathrm{~kg}^{-1}, 1 \mathrm{~m} \mathrm{~s}^{-1}$, and $30^{\circ}$, the percentages of the HR are $71 \%$ for the air temperature data, 59\% for the specific humidity, $66 \%$ for wind speed, and $41 \%$ for wind direction. Overall, the evaluation demonstrates good performance of WRF-PUCM under the current configuration (Table 1). This evaluation also provides some measure of uncertainty in the city-scale analyses of the effects of GRs.

\subsection{Numerical Experimental Design}

To assess the city-scale effects of GRs six sets of runs were undertaken

1. default scenario (DFT) as a benchmark, where the roof is characterized with $100 \%$ conventional roofs (as discussed in section 2.2);

2. green roof scenario (GR) with $100 \%$ coverage of vegetation over roofs, which is to demonstrate the maximum potential of GR-based mitigation strategies;

3. four other GR proportions ( $10 \%, 20 \%, 50 \%$, and $80 \%)$.

The GRs' thermal effectiveness relates to their radiative (e.g., reflectivity), conduction (e.g., thermal conductivity), and convection partitioning (e.g., enhanced evaporation) processes. Although the albedo of sedum GR surfaces (0.2-0.3) is higher than that of dark membranes in conventional roofs (0.03-0.15), such a difference is not sufficient to explain the cooling effects of GRs [Gaffin et al., 2009]. If GRs are assigned high albedos (e.g., 0.7-0.85), the estimated cooling effects of GRs are similar to highly reflective roofs [Rosenzweig et al., 2006], implying a slight increase in roof albedo may not significantly improve the thermal performance. As the thermal effect of highly reflective surfaces have been extensively studied [e.g., review by Yang et al., 2015] this effect is removed here by using identical albedo values for both the conventional and green roofs. The other characteristics used in the model runs are given in Table 3.

\section{Results and Discussion}

\subsection{Impact of GRs on the Near-Surface Micrometeorology}

The impact of GRs on the near-surface micrometeorology is examined first through six indicators: air temperatures at $2 \mathrm{~m}$ agl (T2; Figure $5 \mathrm{a}$ ) and at the first model level (Ta; Figure 5b), air specific humidity at $2 \mathrm{~m}$

Table 2. Cover Fractions of Urban Facets Under Different Scenarios (DFT and GR Denote the Default and Green Roof Scenarios, Respectively)

\begin{tabular}{lcc} 
Facet & Surface & Coverage Fraction \\
\hline Roof & conventional & 1.0 (DFT), $0.0(\mathrm{GR})$ \\
& green & 0.0 (DFT), 1.0 (GR) \\
Wall & brick & 0.9 \\
& glass & 0.1 \\
Ground & concrete & 0.5 \\
& asphalt & 0.3 \\
& grass & 0.2 \\
\hline
\end{tabular}
agl (Q2; Figure $5 \mathrm{c}$ ) and at the first model level (Qa; Figure 5d), and wind speed at $10 \mathrm{~m}$ agl (UV10; Figure 5e) and at the first level (UVa; Figure $5 f$ ). In the model, the first vertical level over UGs is at a height of $\sim 77 \mathrm{~m}$. In the version of WRF used in this study (version 3.4), the surface diagnostics variables (e.g., T2, Q2, and UV10) are computed 

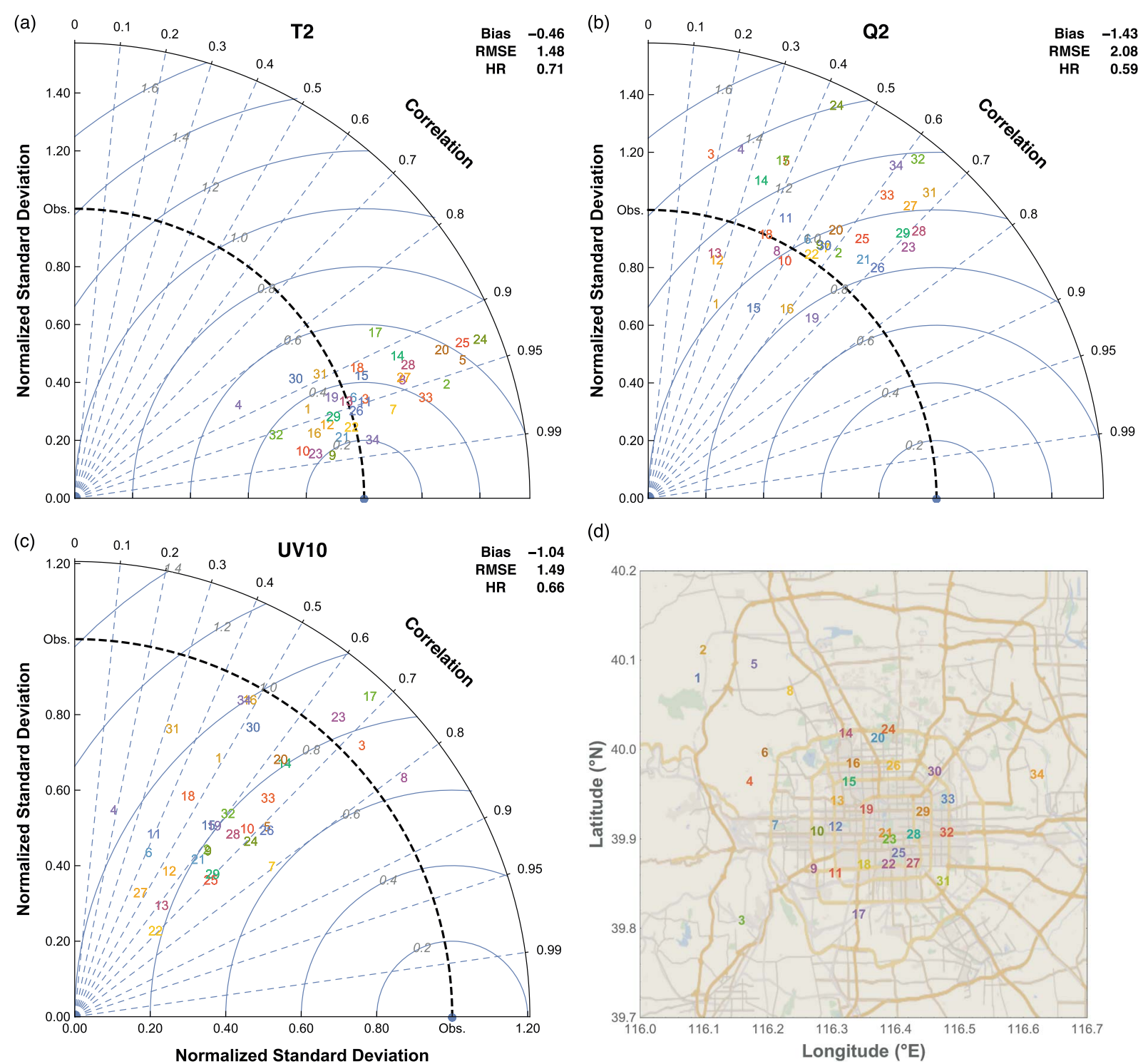

Figure 4. Evaluation of WRF-PUCM performance for (a) air temperature T2 $\left(2 \mathrm{~m}\right.$ agl, $\left.{ }^{\circ} \mathrm{C}\right)$, (b) specific humidity Q2 $\left(2 \mathrm{~m}\right.$ agl, $\left.\mathrm{g} \mathrm{kg}^{-1}\right)$, and (c) wind speed UV10 (10 $\mathrm{m}$ agl, $\mathrm{m} \mathrm{s}^{-1}$ ) using measurements at (d) 34 CMA sites across Beijing. Statistics include correlation, normalized standard deviation, and normalized root-mean-square error shown in Taylor diagram plus average bias, RMSE, and hit rate ([Schlunzen and Katzfey, 2003] criteria for T2, Q2, and UV10 are $2^{\circ} \mathrm{C}, 2 \mathrm{~g} \mathrm{~kg}{ }^{-1}$, and $1 \mathrm{~m} \mathrm{~s}^{-1}$, respectively). The Taylor diagrams display the correlation coefficient in relation to the polar axis comparing hourly values, the normalized standard deviation in relation to the horizontal axis, and the normalized RMSE in relation to the internal circular axes [Taylor, 2001].

based on a scheme in which the urban signature is missing (see discussions in Loridan et al. [2013] and Li and Bou-Zeid [2014]). In contrast, the atmospheric prognostics (e.g., Ta, Qa, and UVa) are obtained with appropriate consideration of urban-atmosphere interactions. As such, we use the surface diagnostics as the direct proxy variables (i.e., T2, Q2, and UV10) for the near-surface micrometeorology and employ the first vertical level prognostics (i.e., Ta, Qa, and UVa) as the responsive variables for the impact of urban surfaces. To assess the impact of GRs on thermal stress, apparent temperatures at two levels (i.e., AT2 and ATa; Figures $5 \mathrm{~g}$ and $5 \mathrm{~h}$, respectively) are calculated, based on the above meteorological diagnostics. The results are temporally averaged to give a $24 \mathrm{~h}$ diurnal cycle and spatially averaged for all 1472 UGs in the GBR to represent the ensemble characteristics across the urban area.

Throughout the day, $\mathrm{T} 2$ is smaller for the GR scenario than for DFT (Figure 5a), with the maximum reduction in the median at noon of $2.5 \mathrm{~K}$. Similar results are found for Ta (Figure $5 \mathrm{~b}$ ), but the maximum reduction of $1.6 \mathrm{~K}$ 
Table 3. Hygrothermal Properties of Materials on Urban Facets ${ }^{a}$

\begin{tabular}{|c|c|c|c|c|c|c|c|c|}
\hline \multirow[b]{2}{*}{ Property } & \multirow[b]{2}{*}{ Units } & \multicolumn{2}{|l|}{ Roof } & \multicolumn{2}{|c|}{ Wall } & \multicolumn{3}{|c|}{ Ground } \\
\hline & & Conventional & Green & Brick & Glass & Concrete & Asphalt & Grass \\
\hline Thermal capacity & $\left(\mathrm{MJ} \mathrm{m}{ }^{-3} \mathrm{~K}^{-1}\right)$ & 2.0 & 1.9 & 1.2 & 1.2 & 2.4 & 1.0 & 1.2 \\
\hline Thermal conductivity & $\left(\mathrm{W} \mathrm{m}^{-1} \mathrm{~K}^{-1}\right)$ & 1.2 & 1.1 & 1.3 & 1.3 & 1.8 & 1.2 & 1.2 \\
\hline Albedo & $(-)$ & 0.3 & 0.3 & 0.25 & 0.25 & 0.4 & 0.15 & 0.1 \\
\hline Emissivity & $(-)$ & 0.95 & 0.95 & 0.95 & 0.95 & 0.95 & 0.95 & 0.93 \\
\hline Saturation water content & $\left(m^{3} m^{-3}\right)$ & - & 0.66 & - & - & - & - & 0.48 \\
\hline Residual water content & $\left(m^{3} m^{-3}\right)$ & - & 0.05 & - & - & - & - & 0.15 \\
\hline $\begin{array}{l}\text { Saturation hydraulic } \\
\text { conductivity }\end{array}$ & $\left(\mathrm{m} \mathrm{h}^{-1}\right)$ & - & 0.42 & - & - & - & - & 0.12 \\
\hline
\end{tabular}

${ }^{a}$ Values are adopted from Wang et al. [2012], except for green roofs from Sun et al. [2013].

occurs at the peak hour. These results indicate that extensive GRs could significantly reduce the near surface air temperature under HWs. Given the relationship between heat-related excess mortality rate (i.e., the heatrelated deaths above a baseline) and UHI intensity estimated in Shanghai by Tan et al. [2009], this effect (i.e., a decrease of $2.5 \mathrm{~K}$ in T2) might be expected to reduce the risk up to 25 per 100,000. The shift in peak time of T2
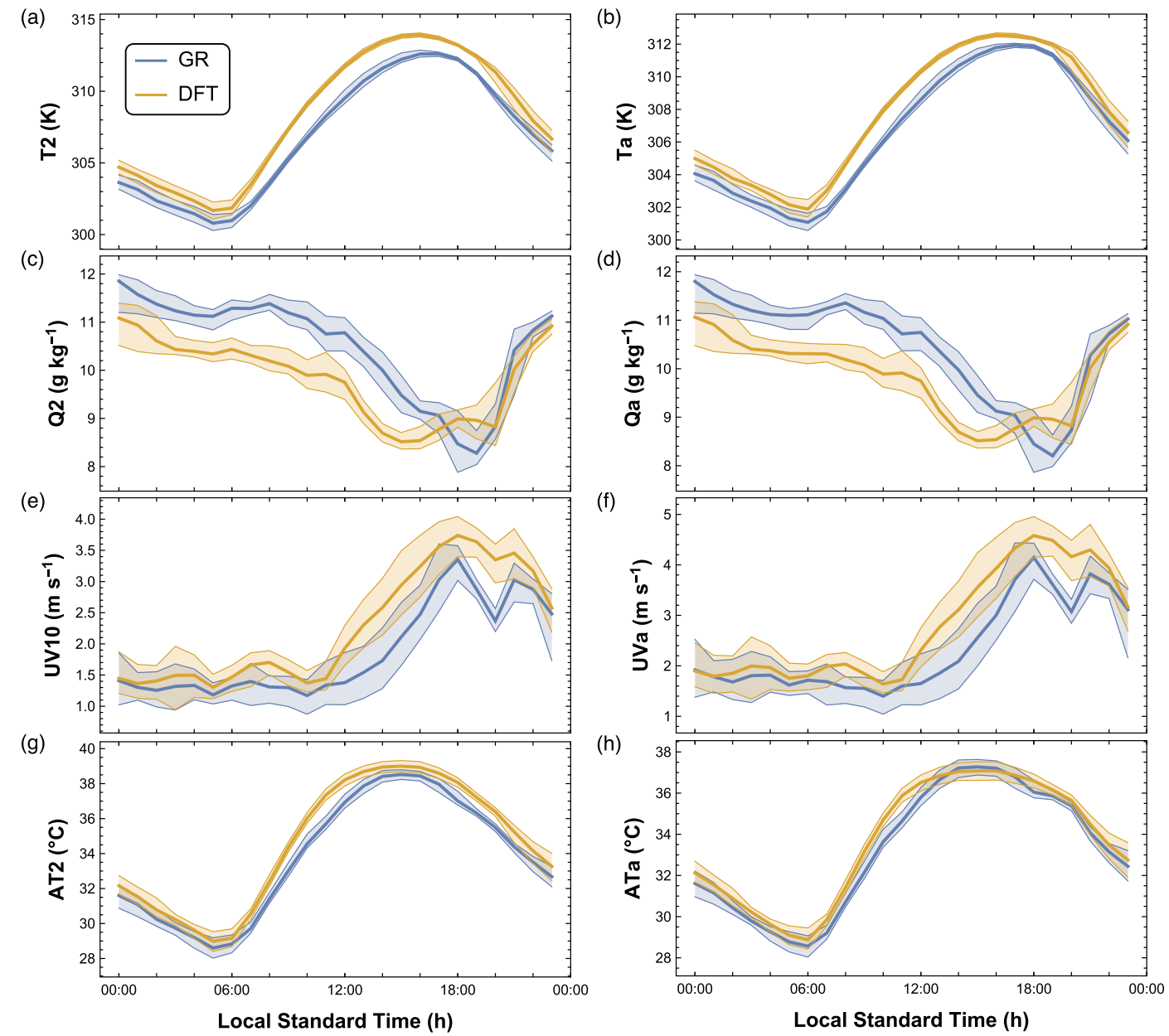

Figure 5. The mean (line) urban grid diurnal cycles and interquartile (shaded) values for WRF-PUCM simulation results under the GR and DFT scenarios. ( left column) Surface diagnostics: (a) the air temperature at $2 \mathrm{~m}$ agl (T2), (c) the air specific humidity at $2 \mathrm{~m}$ agl (Q2), (e) the wind speed at $10 \mathrm{~m}$ agl (UV10), and (g) the apparent temperature at $2 \mathrm{~m}$ agl (AT2); (right column) prognostics at the first vertical level: (b) the air temperature (Ta), (d) the air specific humidity (Qa), (f) the wind speed (UVa), and (h) the apparent temperature (ATa). 


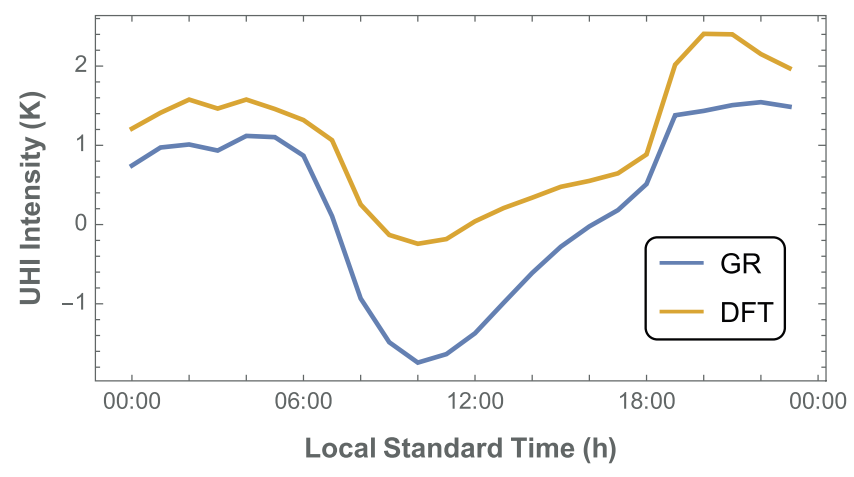

Figure 6. The diurnal cycle of T2-based UHI intensity under the GR and DFT scenarios based on comparison of the urban area and rural areas (see Figure 3b: the inner disk and outer dashed ring denote urban and rural areas, respectively).

tilation (whether residents have windows open or not) and air conditioning demand. and Ta under GR, approximately $2 \mathrm{~h}$ later than under DFT, can be attributed to extra heat storage [Kuo, 1968] of soil-vegetation layers of GRs. We note that this extra heat storage may lead to a warmer nighttime outdoor thermal environment [Grimmond and Oke, 1999]. However, the added thermal inertia to the roof insulation due to GRs would be expected to decrease the heat conducted into the buildings, resulting in a decreased internal cooling need [Ramamurthy et al., 2015]. Under this scenario, decisions about ven-
ge-scale impacts on thermal comfort
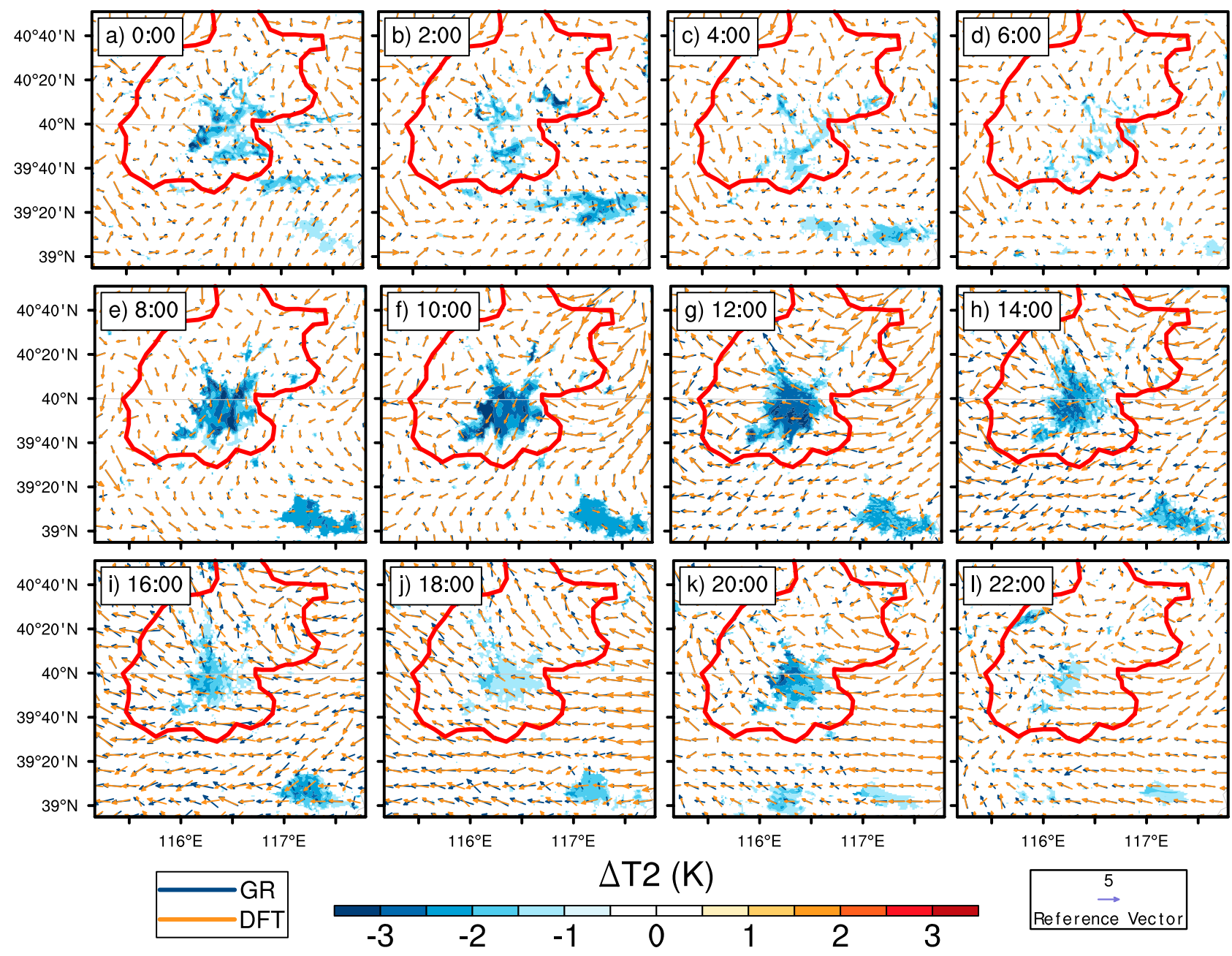

Figure 7. The spatial patterns of $\mathrm{T} 2$ and UV10 at 12 different times. Shadings are the difference in $\mathrm{T} 2$ (i.e., $\Delta \mathrm{T} 2=\mathrm{T} 2_{\mathrm{GR}}-\mathrm{T} 2_{\mathrm{DFT}}$ ). The arrows are UV10 vectors for GR (blue) and DFT (orange) scenarios respectively. The areas with $|\Delta \mathrm{T} 2|<0.5 \mathrm{~K}$ are masked. The red-edged polygon denotes the Greater Beijing Region. 


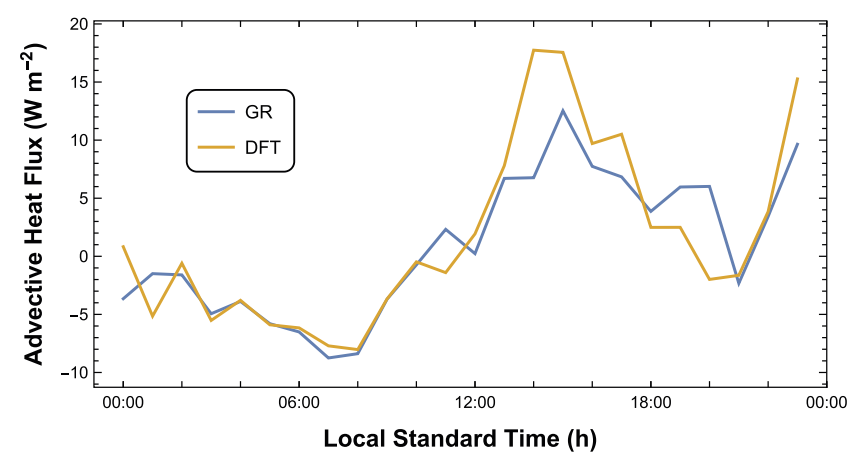

Figure 8. The averaged diurnal cycle of advective heat flux within the $2500 \mathrm{~m}$ agl atmosphere over urban grids under the GR and DFT scenarios. The advective heat flux $Q_{A}$ for an urban grid is calculated as $Q_{A}=\int_{z_{0}}^{z_{h}} C_{p}\left(u(z) \frac{\partial \theta(z)}{\partial x}+v(z) \frac{\partial \theta(z)}{\partial y}\right) d z$, where $C_{p}$ is the volumetric heat capacity of air at a constant pressure, $u(z)$ and $v(z)$ are the meridional and zonal wind speed at height $z$, and $\theta(z)$ is the potential temperature at height $z$. Results for shallower atmospheric columns (not shown here) demonstrate similar diurnal patterns but with smaller magnitudes and relative orders of GR and DFT as indicated in this figure.

The simulations show air humidity would increase with GRs compared to DFT conditions (Q2 and Qa; Figures 5c and $5 \mathrm{~d}$ ). The largest differences occur in the morning, the smallest in the early evening. The GRs' active evaporative period is important in controlling the differences. The combined effect of wind speed changes, and decreased active evapotranspiration causes air humidity to be lower than the DFT in the late afternoon.

The wind speed reduction by GRs varies through the day (UV10 and UVa; Figures 5e and 5f), with the maximum decrease in the early evening and the minimum decrease at midnight. In the afternoon, when the evapotranspiration rates from GRs are large, the difference is more evident. Thus city-wide implementation of GRs may affect the urban-atmospheric interactions beyond the local building or block scales (see later sections).

Thermal stress is reduced by GRs throughout the day (AT2 and ATa; Figures $5 \mathrm{~g}$ and $5 \mathrm{~h}$, respectively) except for early afternoon (i.e., 13:00-15:00 local standard time (LST)) at the first vertical level (Figure 5h). Unfortunately, in terms of mitigation of thermal stress, the largest reduction is in the morning rather than in the afternoon. However, there is a net improvement in thermal stress (the median reductions are $1.0^{\circ} \mathrm{C}$ and $0.6^{\circ} \mathrm{C}$ for $\mathrm{AT} 2$ and $\mathrm{ATa}$, respectively), which is beneficial to the area. In addition, the strongest correlation of apparent temperature is with the air temperature (equation (1)), implying that the changes in air temperature have larger impacts on the apparent temperature than other determinants.

\subsection{Impact of GRs on the UHI Effect}

The Greater Beijing Region is surrounded by mountains to the west and north and by cropland to the east and south (Figure 3b). Given the relatively high altitude of the northwest mountains ( 2000 m), the urbanrural contrast is most appropriately quantified by the differences that result from the modifications of the central built-up area and the croplands. As such, the differences in T2 values for urban and cropland grids (shown in Figure 3b) are used to determine an UHI intensity.

Changes in UHI intensity between the GR and DFT scenarios are more evident in the daytime but comparable at night (Figure 6). Notably under GR, there is a daytime cool island effect, whereas an UHI effect occurs under DFT. The change in intensity is $1.8 \mathrm{~K}$. Such cool island effects have been observed in cities such as semiarid Sacramento (California) and Phoenix (Arizona) areas. This has been attributed to the contrasting surface energy balance (SEB) characteristics between urban-rural areas [Grimmond et al., 1993; Georgescu et al., 2011]. Although the UHI effect can still be observed in the evening (e.g., at 20:00 h) under the modeled GR scenario, its maximum intensity becomes weaker than under DFT ( $1.4 \mathrm{~K}$ compared to $2.4 \mathrm{~K}$ ).

\subsection{Impact of GRs on the Regional Circulation}

As the urban-rural thermal contrasts may trigger secondary urban-rural circulations [Lemonsu et al., 2005; Klein, 2012], the impact of GRs on the regional circulation is examined. 

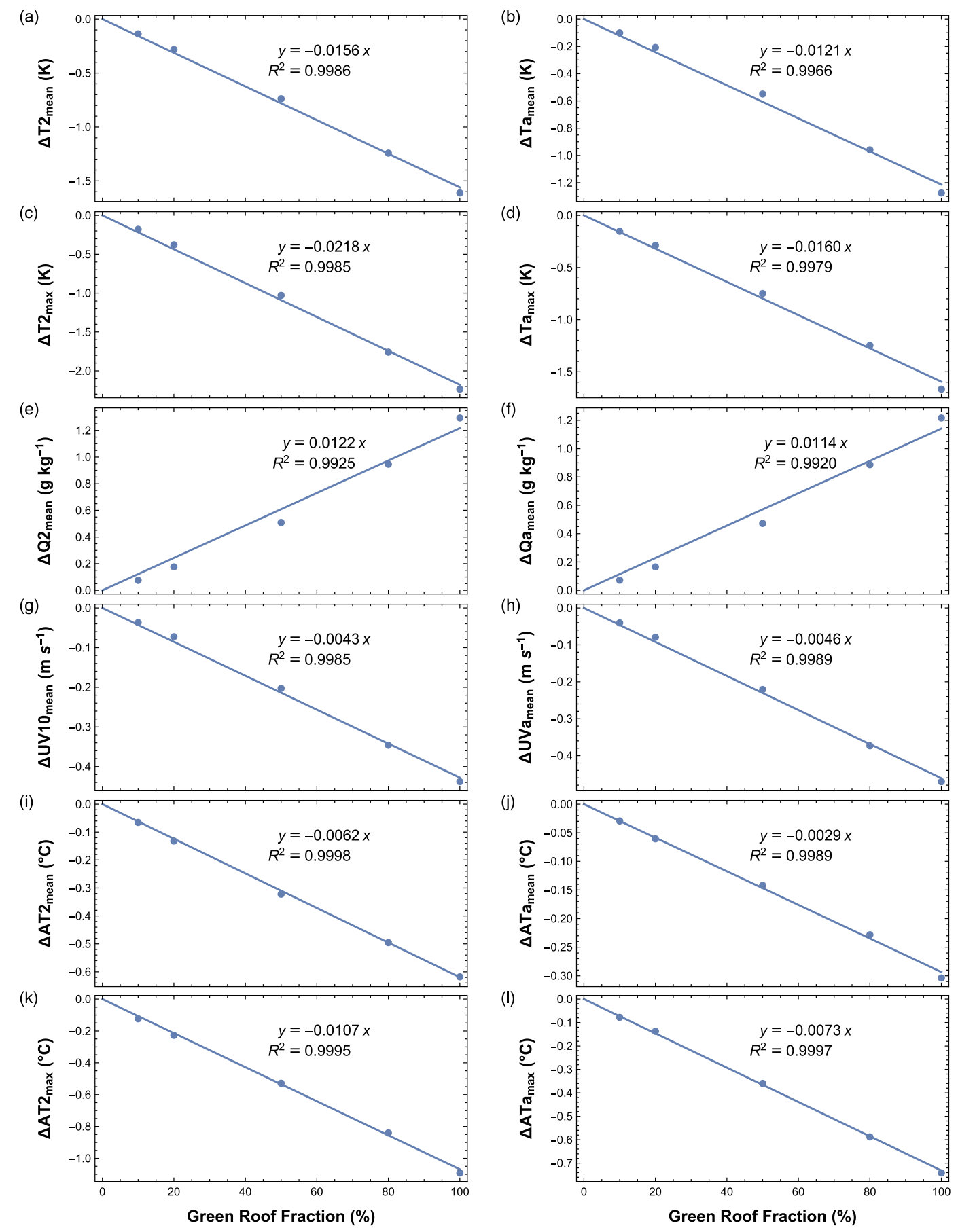

Figure 9. The city-scale impacts of green roofs as a function of GR coverage fraction on daily values of (a) maximum $T 2$, (b) maximum Ta, (c) mean T2, (d) mean Ta, (e) mean Q2, (f) mean Qa, (g) mean UV10, (h) mean UVa, (i) mean AT2, (j) mean ATa, (k) maximum AT2, and (I) maximum ATa. The dots represent the simulation results with lines for the regression relations.

Although differences (GR-DFT) in T2 are found for the UGs, the differences for non-UGs are relatively small (Figure 7, shading), with the largest differences around noontime (Figures $7 \mathrm{f}-7 \mathrm{~h}$ ) and the smallest differences at night (Figures 7a, 7b, and 7l). The larger difference in T2 at 20:00 than at 16:00 is caused by a shift in the peak times of T2 compared to DFT and to GR (Figure 5a). The evaporative cooling effect is important in the daytime. The performance of GR is ultimately controlled by photosynthetically active radiation and the soil moisture availability, which controls the evapotranspiration [Sun et al., 2013]. 

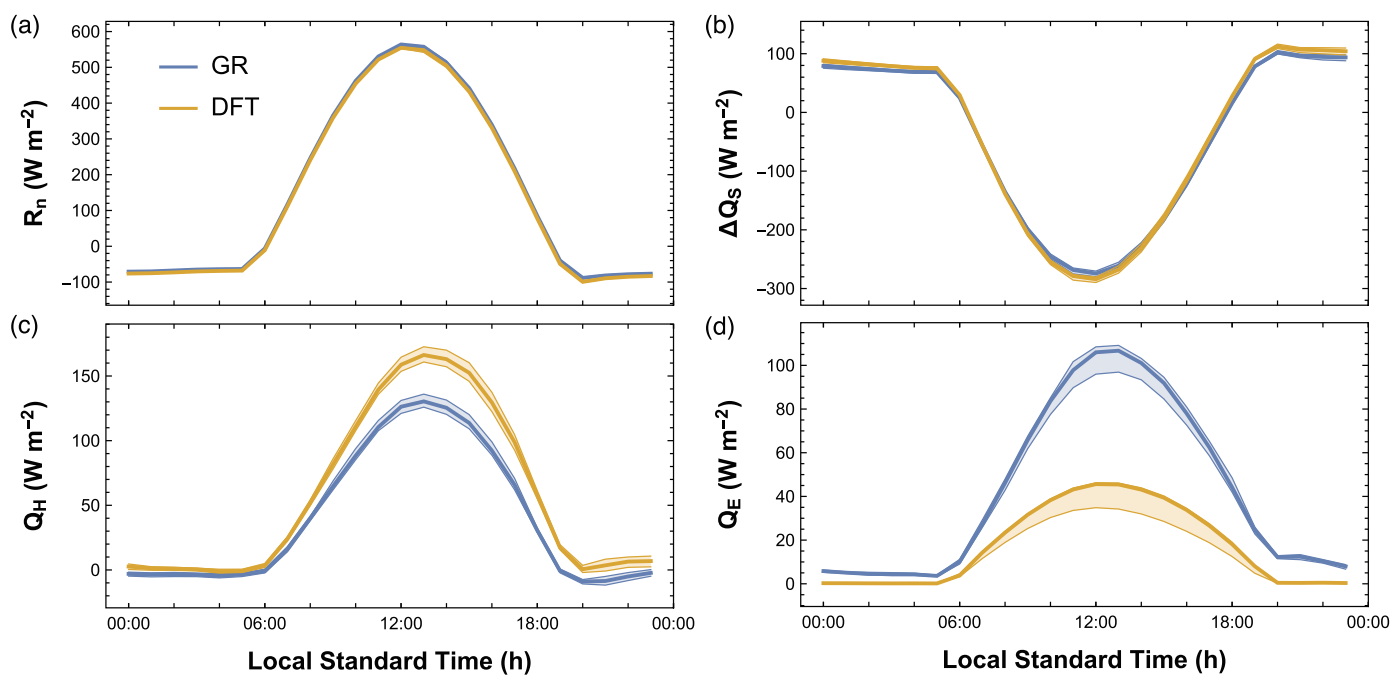

Figure 10. The mean (line) urban grid diurnal cycles (line) and interquartile (shaded) values for WRF-PUCM simulation results (positive upward) under the GR and DFT scenarios: (a) the all wave net radiation $\left(R_{n}\right)$, (b) the storage heat flux $\left(\Delta Q_{S}\right)$, (c) the sensible heat $\left(Q_{H}\right)$, and (d) the latent heat flux $\left(Q_{E}\right)$.

The near surface wind regimes before $08: 00 \mathrm{~h}$ are generally similar (Figures $7 \mathrm{a}-7 \mathrm{~d}$, vectors). The wind regimes start to diverge as the urban temperature differences become larger in the morning (Figures $7 e$ and $7 f$ ) due to the enhanced evaporative cooling. The divergence becomes more apparent from noon (Figures $7 \mathrm{~g}$ and $7 \mathrm{~h}$ ). The GR scenario causes some diversion of the northeasterly wind at the urban edge of GBR (Figures 7g-7i). The southerly winds $(16: 00 \mathrm{~h})$ are enhanced by the GR as they pass over the GBR, but the diversion remains consistent with the reduced wind speeds (Figure 7i). The outskirts of GBR are as hot as in the city in the afternoon (Figure 6) under current conditions (DFT). This encourages advective heating into the city in the afternoon (Figure 8). Whereas with the GR, in addition to the cool island effect (Figure 6), the reduction of the rural wind penetration contributes to a cooler urban area. In the evening, however, when the UHI effect is best developed (Figure 6), the easterly wind under the GR scenario becomes strong enough to enter into the UGs of GBR (Figures 7j-7l). This suggests that the strong nighttime UHI effect can facilitate the urban-rural circulation when the evaporative cooling becomes weaker in the evening, even if the UGs are still cooler under GR as compared with DFT (Figures 7j-7l).

\subsection{Impacts of GR Coverage}

For the scenario with $100 \%$ cover of GRs, there are significant impacts on the near surface meteorology at the city scale, and on the temperature and wind regimes at the regional scale. Given this extreme scenario would take many years to occur in reality, the impact of a changing percentage of GR coverage is considered.

In general, there are strong linear relations with the GR fraction and impacts (Figure 9). This implies that increases in GR cover immediately start to modify the near surface meteorological conditions. Based on the regression analysis (Figures 9a and 9c), a 10\% increase in the GR coverage fraction could lead to decreases of $0.16 \mathrm{~K}$ and $0.22 \mathrm{~K}$ in the mean and maximum T2. Similarly, the same increase in the GR coverage fraction results in deceases of $0.12 \mathrm{~K}$ (Figure 9b) and $0.16 \mathrm{~K}$ (Figure 9d) in the mean and maximum Ta. These are consistent with the findings of $\mathrm{Li}$ and Bou-Zeid [2014], i.e., reduction of $0.05^{\circ} \mathrm{C}$ in $\mathrm{T} 2 \mathrm{UHI}$ intensity, predicted with a $10 \%$ increase in the GR coverage in city-scale simulations, but with a quasi-linear reduction in UHI intensity. The linear increases in mean Q2 and mean Qa with the GR coverage fraction (Figures 9e and 9f) suggest a homogeneous moisture supply to the air at the city scale. The linear reductions in mean UV10 and mean UVa (Figures $9 \mathrm{~g}$ and $9 \mathrm{~h}$ ) with increasing GR coverage fraction imply a stronger reduction in wind speeds by more GRs. The combined vulnerable indicator, AT2 and ATa, is also predicted to be linearly reduced with increasing GR coverage fraction for both the mean (Figures $9 \mathrm{i}$ and $9 \mathrm{j}$ ) and maximum (Figures $9 \mathrm{k}$ and 9l) values. It should be noted though, that even with $100 \%$ GR there are still large impervious areas (e.g., roads). 

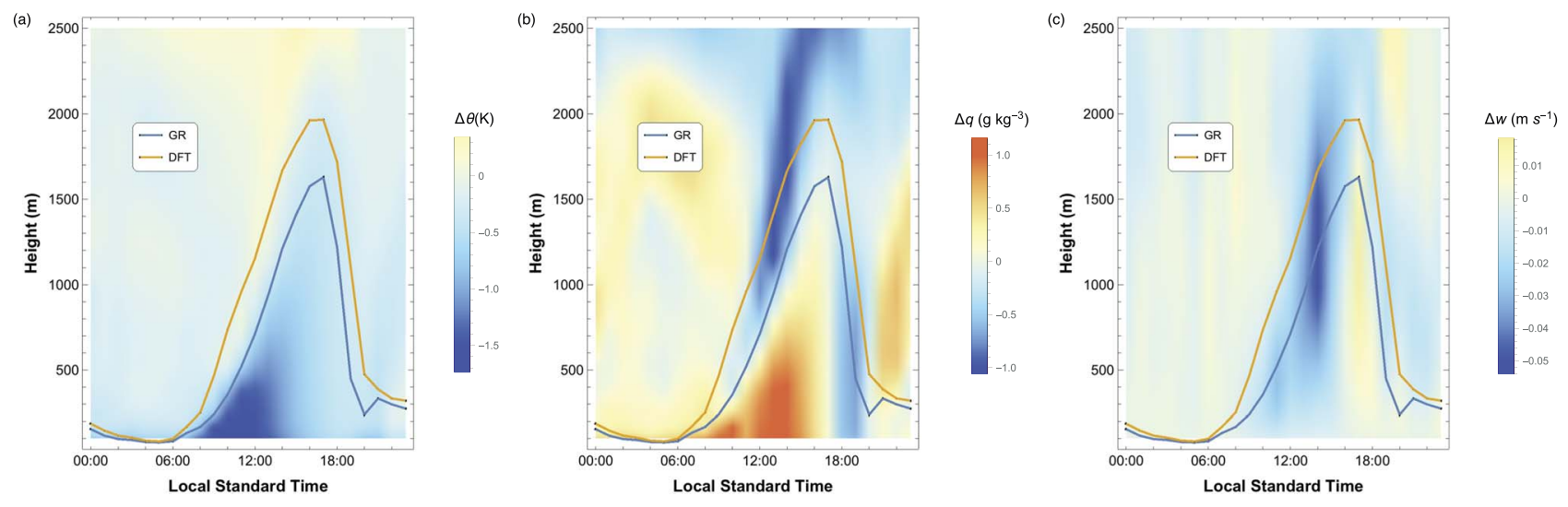

Figure 11. The averaged diurnal variation in PBL characteristics: the shading shows the differences in (a) the potential temperature $\left(\theta_{\mathrm{GR}}-\theta_{\mathrm{DFT}}\right)$, (b) the specific humidity $\left(q_{\mathrm{GR}}-q_{\mathrm{DFT}}\right)$, and $(c)$ the vertical velocity $\left(w_{\mathrm{GR}}-w_{\mathrm{DFT}}\right)$ between the GR and DFT simulations, while the blue and orange lines denote the diurnal cycles of planetary boundary layer height under the GR and DFT scenarios respectively.

\subsection{Modifying Mechanism of GRs}

Next, the mechanisms by which GRs have effects at the city-scale are investigated. Given the linear relation between the modifying effects and GR cover fraction (section 3.4), only the full GR (i.e., 100\% vegetation coverage of roofs) and DFT scenarios are analyzed.

The urban climate modification by GRs results from coupled changes in the energy and water balances. The largest modification in the net all wave radiation $\left(R_{n}\right)$ (Figure 10a) is caused by cooler daytime surface temperatures from the GR. These reduce the longwave wave loss, making the $R_{n}$ slightly larger during the daytime $\left(\sim 30 \mathrm{~W} \mathrm{~m}^{-2}\right)$. The cooler air temperature effects cause a much smaller modification. The storage heat flux $\Delta Q_{S}$ is reduced in the middle of the day (Figure 10b), again because of the reduced surface temperatures, but is enhanced in the late afternoon and therefore results in the greater loss at night. The slower heating of the soil water relative to other building materials is important. The largest change is in the partitioning of the turbulent heat fluxes, with the peak sensible heat flux $Q_{H}$ reduced by $25 \%$ compared to the DFT (Figure 10c) and with more energy dissipated as latent heat (Figure 10d). As the change in the near surface air temperature is directly governed by the sensible heat flux, the reduction in T2 and Ta (Figures 5a and $5 b$ ) is expected.

In addition to the heating directly above the surface, the entrainment at the top of planetary boundary layer (PBL) modifies local atmospheric conditions, particularly during heat waves. Miralles et al. [2014] found that soil moisture deficit and heating from entrainment intensifies the thermal stress during extreme temperatures under heat waves, with deeper than usual PBLs. The PBL characteristics for the two cases (Figures $11 \mathrm{a}$ and $11 \mathrm{~b}$ ) show an $\sim 1.5 \mathrm{~K}$ decrease of potential temperature and an $\sim 1.0 \mathrm{~g} \mathrm{~kg}^{-1}$ increase of specific humidity within the lower $500 \mathrm{~m}$ of the daytime PBL (GR-DFT), whereas the nocturnal regimes are comparable. Concomitant with the daytime decrease in potential temperature, there is an $\sim 450 \mathrm{~m}$ reduction in the PBL height simulated in the midday/afternoon period (12:00-16:00 LST) under the GR scenario. This implies that less atmospheric heating will be caused via PBL entrainment because of a reduction in gradient caused by the lower potential temperature at a lower altitude. As the entrainment heat and variation in PBL height are essentially driven by the surface heating [Stull, 1988; Pal et al., 2012; Lac et al., 2013; Pal et al., 2015], the altered SEB under HWs is important (Figure 10). Although humidity changes impact thermal comfort along with the shallower PBL under GR and reduced entrainment of dry air (Figure 11b), the improved thermal comfort by GRs (see Figures $5 \mathrm{~g}$ and $5 \mathrm{~h}$ ) again shows the dominance of high temperature in thermal stress under HWs.

Along with the surface and PBL heating, the wind regime within the PBL is also modified by GRs under HWs (Figures 11c and 12). This is particularly so for HWs when the synoptic winds are weak [Perkins, 2015] and the urban flow pattern is driven primarily by local thermals [Klein, 2012]. Compared with DFT, the strong noontime surface cooling by GRs reduces the potential temperature within the bottom $\sim 500 \mathrm{~m}$ of PBL over UGs 


\section{AGU Journal of Geophysical Research: Atmospheres}
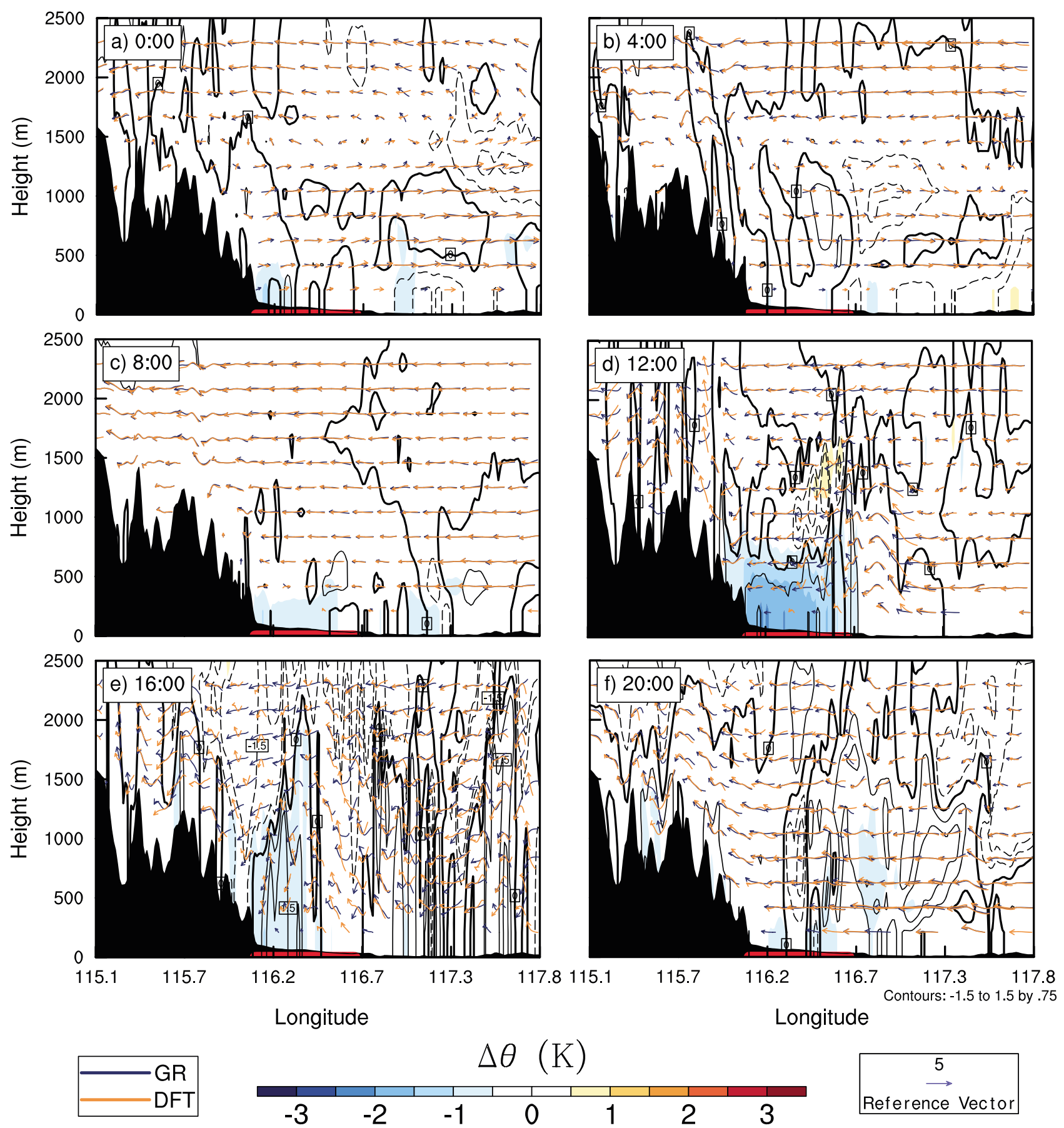

Figure 12. The east-west cross section through $D 03$ center $\left(39.8^{\circ} \mathrm{N}, 116.5^{\circ} \mathrm{E}\right)$ of PBL characteristics at six different times. The shading and contours show the differences in the potential temperature (i.e., $\theta_{\mathrm{GR}}-\theta_{\mathrm{DFT}}$ ) and the specific humidity (i.e., $q_{\mathrm{GR}}-q_{\mathrm{DFT}}$ ) between the $\mathrm{GR}$ and $\mathrm{DFT}$ scenarios, respectively. The blue and orange vectors denote the circulation pattern within the PBL under the GR and DFT scenarios, respectively. The black color shows the mountains and red the urban grids (see Figure 3b).

(Figures 11a and 12d), leading to weaker vertical thermal mixing (Figure 11c and Figures 12d and 12e) and thus reduced wind speeds (Figures $12 \mathrm{~d}$ and $12 \mathrm{e}$ and Figures $5 \mathrm{e}$ and $5 \mathrm{f}$ ). The reduced wind speed dampens mechanical shearing [Stull, 1988; Klein, 2012], which reduces the turbulent mixing, in part contributing to the smaller sensible heat flux compared to DFT (Figure 10c).

Thus, the modifying mechanisms of GRs includes (1) altering the underlying SEB by changing the available energy and its partitioning, favoring latent heat, which leads to less sensible heat; (2) lowering the PBL height 
to dampen the atmospheric heating through entrainment at the PBL top; and (3) weakening the vertical mixing to reduce the turbulent heating.

\section{Concluding Remarks}

One-way nested WRF-PUCM simulations of air temperature (at $2 \mathrm{~m}$ agl), air humidity (at $2 \mathrm{~m}$ agl), and wind speed (at $10 \mathrm{~m}$ agl) in the Greater Beijing Region were evaluated at 34 China Meteorological Administration (CMA) sites. Overall, the evaluation demonstrates good performance of WRF-PUCM under the current configuration (mean correlation coefficients of $0.94,0.51$, and 0.59 , respectively; root-mean-square error (RMSE) of $1.48 \mathrm{~K}, 2.08 \mathrm{~g} \mathrm{~kg}^{-1}$, and $1.49 \mathrm{~m} \mathrm{~s}^{-1}$, respectively) and provides some measure of uncertainty for the subsequent city-scale analyses.

To investigate reductions in thermal stress under heat waves from green roofs, six green roof cover fractions $(0,10,20,50,80$, and $100 \%)$ were simulated. With $100 \%$ cover of vegetated roofs, air temperature was reduced $\left(\Delta \mathrm{T} 2_{\max }=2.5 \mathrm{~K}, \Delta \mathrm{Ta}_{\max }=1.6 \mathrm{~K}\right)$, air humidity increased $\left(\Delta \mathrm{Q} 2_{\max }=1.3 \mathrm{~g} \mathrm{~kg}^{-1}, \Delta \mathrm{Qa}_{\max }=1.3 \mathrm{~g} \mathrm{~kg}^{-1}\right)$, wind speed reduced $\left(\Delta U V 10_{\max }=1.0 \mathrm{~m} \mathrm{~s}^{-1}, \Delta U \mathrm{Ua}_{\max }=1.1 \mathrm{~m} \mathrm{~s}^{-1}\right)$, and thermal stress reduced $\left(\Delta \mathrm{AT} 2_{\max }=1.7^{\circ} \mathrm{C}, \Delta \mathrm{ATa} \mathrm{a}_{\max }=1.2^{\circ} \mathrm{C}\right)$. Given the setting of Beijing, this full cover $\mathrm{GR}$ scenario could be expected to change the current $\mathrm{HW}$ condition of an urban heat island to a cool island in the middle of the day. The modifying effects of GRs extend to the surroundings of the urban environment with the regional temperature and wind speed regimes significantly affected. The daytime DFT regional circulation penetrates into the urban core area, whereas under the full GR scenario the circulations is inhibited, with less advected heat into the urban area. The simulations reveal that reductions in air temperature, wind speed, and apparent temperature, and increases in air humidity, increase linearly with GR coverage fraction.

Changes in the SEB include decreased sensible heat flux and increased latent heat flux. This leads to a shallower PBL and lower potential temperatures within the $2500 \mathrm{~m}$ agl atmosphere in the daytime. As the PBL is capped by an inversion, entrainment through the PBL top will heat up the lower atmosphere. Under heat wave conditions, a deeper PBL may develop due to intensified convection, leading to more entrainment of warmer air [Miralles et al., 2014]. Model runs suggest under GR conditions a shallower PBL with reduced entrainment. Thus, the modifying mechanisms of GR stem from the alteration in available energy and its partitioning into turbulent fluxes from the underlying surface, leading to dampened convection and less entrainment heating due to a shallower PBL.

This study, of the most intense heat wave period in 2010 for Beijing, suggests that extending simulations to a wider range of locations and conditions is warranted to help generalize these findings. These simulations should include not only discrete towns and cities in different regional settings but also rapidly developing conurbations (consisting of several merging cities) where optimal configurations of GRs may benefit regional as well as city climates.

Acknowledgments

T.S. acknowledges the support from NSFC under grants 51190092 and 51409147 and China Postdoctoral Science Foundation under grant 2015T80093. S.G. and T.S. acknowledge the support of the Met Office/Newton Fund CSSP-China. The simulations were performed on the supercomputing clusters of Tsinghua National Laboratory for Information Science and Technology. The authors also thank the editor, L. Ruby Leung, and the three reviewers for their insightful and constructive comments that significantly improve the quality of this work. The data for this paper are available through request to the corresponding author via sunting@tsinghua.edu.cn.

\section{References}

Berardi, U., A. GhaffarianHoseini, and A. GhaffarianHoseini (2014), State-of-the-art analysis of the environmental benefits of green roofs, Appl. Energ., 115, 411-428, doi:10.1016/j.apenergy.2013.10.047.

Best, M. J., and C. S. B. Grimmond (2015), Key conclusions of the first international urban land surface model comparison project, Bull. Am. Meteorol. Soc., 96(5), 805-819, doi:10.1175/BAMS-D-14-00122.1.

Buzan, J. R., K. Oleson, and M. Huber (2015), Implementation and comparison of a suite of heat stress metrics within the Community Land Model version 4.5, Geosci. Model Dev., 8(2), 151-170, doi:10.5194/gmd-8-151-2015.

Carson, T. B., D. E. Marasco, P. J. Culligan, and W. R. McGillis (2013), Hydrological performance of extensive green roofs in New York City: Observations and multi-year modeling of three full-scale systems, Environ. Res. Lett., 8(2), 024036, doi:10.1088/1748-9326/8/2/024036.

Chen, F., and J. Dudhia (2001), Coupling an advanced land surface-hydrology model with the Penn State-NCAR MM5 modeling system. Part I: Model implementation and sensitivity, Mon. Weather Rev., 129(4), 569-585, doi:10.1175/1520-0493(2001)129<0569:CAALSH > 2.0.CO;2.

Chen, F., et al. (2011), The integrated WRF/urban modelling system: Development, evaluation, and applications to urban environmental problems, edited by M. Roth, R. Emmanuel, T. Ichinose, and J. Salmond, Int. J. Climatol., 31(2), 273-288, doi:10.1002/joc.2158.

Dou, J., Y. Wang, R. Bornstein, and S. Miao (2015), Observed spatial characteristics of Beijing urban climate impacts on summer thunderstorms, J. Appl. Meteorol. Climatol., 54(1), 94-105, doi:10.1175/JAMC-D-13-0355.1.

Dudhia, J. (1989), Numerical study of convection observed during the winter monsoon experiment using a mesoscale two-dimensional model, J. Atmos. Sci., 46(20), 3077-3107, doi:10.1175/1520-0469(1989)046<3077:NSOCOD>2.0.CO;2.

Ek, M. B., K. E. Mitchell, Y. Lin, E. Rogers, P. Grunmann, V. Koren, G. Gayno, and J. D. Tarpley (2003), Implementation of Noah land surface model advances in the National Centers for Environmental Prediction operational mesoscale Eta model, J. Geophys. Res., 108(D22), 8851, doi:10.1029/2002JD003296.

Gaffin, S. R., R. Khanbilvardi, and C. Rosenzweig (2009), Development of a green roof environmental monitoring and meteorological network in New York City, Sensors (Basel), 9(4), 2647-2660, doi:10.3390/s90402647. 
Georgescu, M., M. Moustaoui, A. Mahalov, and J. Dudhia (2011), An alternative explanation of the semiarid urban area "oasis effect", J. Geophys. Res., 116, D24113, doi:10.1029/2011JD016720.

Georgescu, M., P. E. Morefield, B. G. Bierwagen, and C. P. Weaver (2014), Urban adaptation can roll back warming of emerging megapolitan regions, Proc. Natl. Acad. Sci. U.S.A., 111(8), 2909-2914, doi:10.1073/pnas.1322280111.

Grimmond, C. S. B., and T. R. Oke (1999), Heat storage in urban areas: Local-scale observations and evaluation of a simple model, J. Appl. Meteorol., 38(7), 922-940, doi:10.1175/1520-0450(1999)038<0922:HSIUAL>2.0.CO;2.

Grimmond, C. S. B., T. R. Oke, and H. A. Cleugh (1993), The Role of "Rural" in Comparisons of Observed Suburban-Rural Flux Differences, pp. 165-165, IAHS Publ.

Grimmond, C. S. B., et al. (2011), Initial results from Phase 2 of the international urban energy balance model comparison, Int. J. Climatol., 31(2), 244-272, doi:10.1002/joc.2227.

Hong, S. Y., J. Dudhia, and S. H. Chen (2004), A revised approach to ice microphysical processes for the bulk parameterization of clouds and precipitation, Mon. Weather Rev., doi:10.1175/1520-0493(2004)132<0103:ARATIM>2.0.CO;2.

Hou, A. (2012), Impacts of Urbanization on Local Hydrometeorological Variables: A Case Study in Beijing, pp. 1-146, Tsinghua Univ..

Hou, A., G.-H. Ni, H. Yang, and Z. Lei (2013), Numerical analysis on the contribution of urbanization to wind stilling: An example over the greater Beijing metropolitan area, J. Appl. Meteorol. Climatol., 52(5), 1105-1115, doi:10.1175/JAMC-D-12-013.1.

Janjic, Z. I. (1990), The step-mountain coordinate: Physical package, Mon. Weather Rev., doi:10.1175/1520-0493(1990)118<1429: TSMCPP $>2.0 . C O ; 2$

Janjić, Z. I. (1996), The surface layer parameterization in the NCEP Eta Model, World Meteorological Organization-Publications-WMO TD, 4-16, doi:10.1029/2002GL015311/full.

Janjić, Z. I. (2002), Nonsingular Implementation of the Mellor-Yamada Level 2.5 Scheme in the NCEP Meso model, National Centers for Environmental Prediction.

Klein, P. M. (2012), Metropolitan Effects on Atmospheric Patterns: Important Scales, Elsevier.

Kuo, H. L. (1968), The thermal interaction between the atmosphere and the Earth and propagation of diurnal temperature waves, J. Atmos. Sci., 25(5), 682-717, doi:10.1175/1520-0469(1968)025<0682:TTIBTA > 2.0.CO;2.

Lac, C., R. P. Donnelly, V. Masson, S. Pal, S. Riette, S. Donier, S. Queguiner, G. Tanguy, L. Ammoura, and I. Xueref-Remy (2013), CO 2 dispersion modelling over Paris region within the $\mathrm{CO}_{2}-$ MEGAPARIS project, Atmos. Chem. Phys., 13(9), 4941-4961, doi:10.5194/acp-13-4941-2013.

Lau, N.-C., and M. J. Nath (2012), A model study of heat waves over north America: Meteorological aspects and projections for the twenty-first century, J. Clim., 25(14), 4761-4784, doi:10.1175/JCLI-D-11-00575.1.

Lau, N.-C., and M. J. Nath (2014), Model Simulation and Projection of European Heat Waves in Present-Day and Future Climates, J Clim., 27(10), 3713-3730, doi:10.1175/JCLI-D-13-00284.1.

Lemonsu, A., G. Pigeon, V. Masson, and C. Moppert (2005), Sea-town interactions over Marseille: 3D urban boundary layer and thermodynamic fields near the surface, Theor. Appl. Climatol., 84(1-3), 171-178, doi:10.1007/s00704-005-0155-y.

Li, D., and E. Bou-Zeid (2013), Synergistic interactions between urban heat islands and heat waves: The impact in cities is larger than the sum of its parts*, J. Appl. Meteorol. Climatol., 52(9), 2051-2064, doi:10.1175/JAMC-D-13-02.1.

Li, D., and E. Bou-Zeid (2014), Quality and sensitivity of high-resolution numerical simulation of urban heat islands, Environ. Res. Lett., 9(5), 055001, doi:10.1088/1748-9326/9/5/055001.

Li, D., E. Bou-Zeid, and M. Oppenheimer (2014), The effectiveness of cool and green roofs as urban heat island mitigation strategies, Environ. Res. Lett., 9(5), 055002, doi:10.1088/1748-9326/9/5/055002.

Loridan, T., C. S. B. Grimmond, S. Grossman-Clarke, F. Chen, M. Tewari, K. Manning, A. Martilli, H. Kusaka, and M. Best (2010), Trade-offs and responsiveness of the single-layer urban canopy parametrization in WRF: An offline evaluation using the MOSCEM optimization algorithm and field observations, Q. J. R. Meteorol. Soc., 136(649), 997-1019, doi:10.1002/qj.614.

Loridan, T., F. Lindberg, O. Jorba, S. Kotthaus, S. Grossman-Clarke, and C. S. B. Grimmond (2013), High resolution simulation of the variability of surface energy balance fluxes across central London with urban zones for energy partitioning, Bound. Layer Meteorol., 147(3), 493-523, doi:10.1007/s10546-013-9797-y.

Meehl, G. A., and C. Tebaldi (2004), More intense, more frequent, and longer lasting heat waves in the 21st century, Science, 305(5686), 994-997, doi:10.1126/science.1098704.

Mellor, G. L., and T. Yamada (1982), Development of a turbulence closure-model for geophysical fluid problems, Rev. Geophys., 20(4), 851-875, doi:10.1029/RG020i004p00851.

Miralles, D. G., A. J. Teuling, C. C. van Heerwaarden, and J. V.-G. de Arellano (2014), Mega-heatwave temperatures due to combined soil desiccation and atmospheric heat accumulation, Nat. Geosci., 7(5), 345-349, doi:10.1038/ngeo2141.

Mlawer, E. J., S. J. Taubman, P. D. Brown, M. J. lacono, and S. A. Clough (1997), Radiative transfer for inhomogeneous atmospheres: RRTM, a validated correlated-k model for the longwave, J. Geophys. Res., 102(D14), 16,663-16,682, doi:10.1029/97JD00237.

National Centers for Environmental Prediction, National Weather Service, NOAA, U.S. Department of Commerce (2000), NCEP FNL operational model global tropospheric analyses, continuing from July 1999, doi:10.5065/D6M043C6.

Oke, T. R. (1982), The energetic basis of the urban heat island, Q. J. R. Meteorol. Soc., 108(455), 1-24, doi:10.1002/qj.49710845502.

Pal, S., et al. (2012), Spatio-temporal variability of the atmospheric boundary layer depth over the Paris agglomeration: An assessment of the impact of the urban heat island intensity, Atmos. Environ., 63, 261-275, doi:10.1016/j.atmosenv.2012.09.046.

Pal, S., M. Lopez, M. Schmidt, M. Ramonet, F. Gibert, I. Xueref-Remy, and P. Ciais (2015), Investigation of the atmospheric boundary layer depth variability and its impact on the 222Rn concentration at a rural site in France, J. Geophys. Res. Atmos., 120, 623-643, doi:10.1002/2014JD022322.

Perkins, S. E. (2015), A review on the scientific understanding of heat waves-Their measurement, driving mechanisms, and changes at the global scale, Atmos. Res., 164-165, 242-267, doi:10.1016/j.atmosres.2015.05.014.

Porson, A., I. N. Harman, S. I. Bohnenstengel, and S. E. Belcher (2009), How many facets are needed to represent the surface energy balance of an urban area? Bound. Layer Meteorol., 132(1), 107-128, doi:10.1007/s10546-009-9392-4.

Qiu, G.-Y., H.-Y. Li, Q.-T. Zhang, W. Chen, X.-J. Liang, and X.-Z. Li (2013), Effects of evapotranspiration on mitigation of urban temperature by vegetation and urban agriculture, J. Integr. Agric., 12(8), 1307-1315, doi:10.1016/S2095-3119(13)60543-2.

Ramamurthy, P., T. Sun, K. Rule, and E. Bou-Zeid (2015), The joint influence of albedo and insulation on roof performance: An observational study, Energ. Build., 93, 249-258, doi:10.1016/j.enbuild.2015.02.040.

Rizwan, A. M., L. Y. C. Dennis, and C. Liu (2008), A review on the generation, determination and mitigation of Urban Heat Island, J. Environ. Sci., 20(1), 120-128, doi:10.1016/s1001-0742(08)60019-4.

Rosenzweig, C., S. Gaffin, and L. Parshall (2006), Green roofs in the New York metropolitan region: Research report.

Saadatian, O., K. Sopian, E. Salleh, C. H. Lim, S. Riffat, E. Saadatian, A. Toudeshki, and M. Y. Sulaiman (2013), A review of energy aspects of green roofs, Renew. Sustain. Energy Rev., 23, 155-168, doi:10.1016/j.rser.2013.02.022. 
Schlunzen, K. H., and J. J. Katzfey (2003), Relevance of sub-grid-scale land-use effects for mesoscale models, Tellus A, 55(3), 232-246, doi:10.1034/j.1600-0870.2003.00017.x.

Skamarock, W. C., and J. B. Klemp (2008), A time-split nonhydrostatic atmospheric model for weather research and forecasting applications, J. Comput. Phys., 227(7), 3465-3485, doi:10.1016/j.jcp.2007.01.037.

Smith, K. R., and P. J. Roebber (2011), Green roof mitigation potential for a proxy future climate scenario in Chicago, Illinois, J. Appl. Meteorol. Climatol., 50(3), 507-522, doi:10.1175/2010JAMC2337.1.

Steadman, R. G. (1984), A universal scale of apparent temperature, J. Climate Appl. Meteorol., 23(12), 1674-1687, doi:10.1175/1520-0450 (1984)023<1674:AUSOAT>2.0.CO;2.

Stensrud, D. J. (2007), Parameterization Schemes: Keys to Understanding Numerical Weather Prediction Models, Cambridge Univ. Press, Cambridge.

Stull, R. (1988), An Introduction to Boundary Layer Meteorology, Springer.

Sun, T., E. Bou-Zeid, Z.-H. Wang, E. Zerba, and G.-H. Ni (2013), Hydrometeorological determinants of green roof performance via a verticallyresolved model for heat and water transport, Build. Environ., 60, 211-224, doi:10.1016/j.buildenv.2012.10.018.

Sun, T., E. Bou-Zeid, and G.-H. Ni (2014), To irrigate or not to irrigate: Analysis of green roof performance via a vertically resolved hygrothermal model, Build. Environ., 73, 127-137, doi:10.1016/j.buildenv.2013.12.004.

Tan, J., et al. (2009), The urban heat island and its impact on heat waves and human health in Shanghai, Int. J. Biometeorol., 54(1), 75-84, doi:10.1007/s00484-009-0256-X.

Tan, M., M. R. Guy, and X. Li (2011), Urban spatial development and land use in Beijing: Implications from London's experiences, J. Geogr. Sci., 21(1), 49-64, doi:10.1007/s11442-011-0828-7.

Taylor, K. E. (2001), Summarizing multiple aspects of model performance in a single diagram, J. Geophys. Res., 106(D7), 7183, doi:10.1029/ 2000JD900719.

Wang, L., D. Li, Z. Gao, T. Sun, X. Guo, and E. Bou-Zeid (2014), Turbulent transport of momentum and scalars above an urban canopy, Bound. Layer Meteorol., 150(3), 485-511, doi:10.1007/s10546-013-9877-z.

Wang, X., and Y. Gong (2010), The impact of an urban dry island on the summer heat wave and sultry weather in Beijing City, Chin. Sci. Bull., 55(16), 1657-1661, doi:10.1007/s11434-010-3088-5.

Wang, Z.-H., E. Bou-Zeid, S. K. Au, and J. A. Smith (2011), Analyzing the sensitivity of WRF's single-layer urban canopy model to parameter uncertainty using advanced Monte Carlo simulation, J. Appl. Meteorol. Climatol., 50(9), 1795-1814, doi:10.1175/2011JAMC2685.1.

Wang, Z.-H., E. Bou-Zeid, and J. A. Smith (2012), A coupled energy transport and hydrological model for urban canopies evaluated using a wireless sensor network, Q. J. R. Meteorol. Soc., 139(675), 1643-1657, doi:10.1002/qj.2032.

Wu, C., and A. T. Murray (2003), Estimating impervious surface distribution by spectral mixture analysis, Remote Sens. Environ., 84(4), 493-505, doi:10.1016/s0034-4257(02)00136-0.

Yang, J., Z.-H. Wang, F. Chen, S. Miao, M. Tewari, J. A. Voogt, and S. Myint (2014), Enhancing hydrologic modelling in the coupled weather research and forecasting-urban modelling system, Bound. Layer Meteorol., 155(1), 1-23, doi:10.1007/s10546-014-9991-6.

Yang, J., Z.-H. Wang, and K. E. Kaloush (2015), Environmental impacts of reflective materials: Is high albedo a "silver bullet" for mitigating urban heat island? Renew. Sustain. Energy Rev., 47(C), 830-843, doi:10.1016/j.rser.2015.03.092.

Yang, J., Z.-H. Wang, M. Georgescu, F. Chen, and M. Tewari (2016), Assessing the impact of enhanced hydrological processes on urban hydrometeorology with application to two cities in contrasting climates, J. Hydrometeorol., 17(4), 1031-1047, doi:10.1175/JHM-D-15-0112.1.

Yang, L., F. Tian, J. A. Smith, and H. Hu (2014), Urban signatures in the spatial clustering of summer heavy rainfall events over the Beijing metropolitan region, J. Geophys. Res. Atmos., 119, 1203-1217, doi:10.1002/2013JD020762. 